\title{
Glimpses of MDA Compliance Survey in North 24 PGNS of West Bengal
}

\author{
Rivu Basu@, Abhishek Paul\#, ShatanikMondal\#, Suresh Chandra Malick\#, \\ Somdipta Bhattacharya\#, ParthaSaha\#, S. K. Lahiri* \\ @ Assistant Professor,\#Post-Graduate traine**Professor and Head of Department, Department of Community \\ Medicine, R.G.Kar.Medical.College, Kolkata, West Bengal.
}

\begin{abstract}
:
Introduction: Lymphatic filariasis is a major public health problem in India. Since 2004, India adopted WHO's strategy of Mass Drug Administration with DEC and Albendazole to eliminate filariasis.

Aims and Objectives: To assess the coverage and compliance of MDA, to document the side effects reported and to identify the factors for non-compliance to MDA.

Material and Methods: A cross-sectional study was conducted among the fourrandomly-selected clusters in the district of North 24-Paraganas, West Bengal, India, covering 558 individualsfrom 128 households, using a predesigned pretested schedule.

Result and Conclusion: MDA Coverages of both DEC and Albendazole in two Rural and two Urban clusters were $97.9 \%, 95.1 \%, 98.1 \%$ and $27.5 \%$ respectively, with overall coverage being $81.9 \%$. The effective coverage was estimated to be $70.7 \%$ which is below the cut-off level ( $\geq 85$ percent) for the programme requirement. $17.9 \%$ surveyed household did not receive any drug. These percentages were highest in one of the urban clusters and lowest in both the rural clusters. Non Complianthouseholds were mostly Hindus and were higher in higher Socio Economic Groups and more educated families. There wereonly $2.3 \%$ of the study subjects who had developed at leastone adverse effectafter consumptionand amongst which nausea and drowsiness were most common.
\end{abstract}

Keywords: Lymphatic filariasis, Compliance, Coverage, Mass drug administration, India.

\section{Introduction}

Lymphatic filariasis, the second most common vector-borne parasitic disease after malaria, commonly known as elephantiasis, is a neglected tropical disease. Currently,1.23 billion people in 58 countries are living in areas where lymphatic filariasis is transmitted and are at risk of being infected.According to WHO, LF is the second most common cause of long-term disability after mental illness. ${ }^{(1)}$ This is a major public health problem in India. An estimated 600 million people are at risk of this infection in 250 endemic districts of 20 states / Union Territories in the country. ${ }^{(2)}$ The National Filaria ControlProgramme (NFCP) was launched in the country in 1955 with the objective of delimiting the problem, toundertake control measures in endemic areas and to train personnel to man the programme.The Government of India issignatory to the World Health Assembly Resolution in 1997 for Global Elimination of Lymphatic Filariasis.The National Health Policy (2002) envisaged elimination of lymphatic filariasis in India by 2015. ${ }^{(3)}$ To achieve this, Mass Drug Administration(MDA) is being implemented in India since 2004. In 2007 India changed its strategy from delivery of DEC alone to delivery of DEC plus Albendazole. The recommendedapproach based on the past experience is "supervised drug administration by door to door visitsupplemented with drug administration at booths and groups" preferably on a single day with twoday mopping up operations, instead of mere distribution of drugs. Thisstrategy is meant to be continued for 5 years or more to the population excluding children below two years,pregnant women and seriously ill persons in affected areas to interrupt transmission of disease. ${ }^{(3)} .12$ districts of West Bengal are endemic for lymphatic filariasis. As per final report of MDA-12(01.03.2012), West Bengal, 79.67\% of the total eligible population was covered under MDA. $\quad{ }^{(4)}$ With this background, Post MDA assessment survey was conducted by Department of Community Medicine, R G Kar Medical College in North 24 Parganas. The objectives of the survey were $t$ o assess the coverage and compliance of MDA, to assess the awareness of community regarding disease \& the existing programme, to document the side effects reported and to identify the factors for non-compliance to MDA.

\section{Materials and Methods}

A community based cross-sectional Coverage Evaluation survey was carried out for a period of one month (i.e. May, 2015) involving the eligible population of the district of North 24 Paraganas. Multistage random sampling was used for the purpose of study. Thus, as per reports of the Chief Medical Officer of Health, the best (Barrackpore II) and worst (Hasnabad) performing blocks were selected according to MDA coverage. 
Similarly, the worst municipality was selected as Birati and best as Madhyamgram. Then one village from each block was also selected by simple random sampling technique (Bilkinda I from Barracpore II and Takipur from Hasnabad). Similarly, randomly Ward 14 was selected from Birati and Ward 24 from Madhyamgram Municipality for the purpose of the study.Finally, 30 house-holds from each village/rural cluster as well as from the selected municipal ward/urban cluster were selected using a systematic random sampling method.From the selected clusters total 128 Households were surveyed covering a total population of 558 out of which 546 became eligible.Inclusion criteria was all individual $\geq 2$ years of age. and exclusion criteria was Pregnant women, severely ill persons. Head of the selected households had been interviewed with a predesigned pretested semi-structured schedule after taking written informed consent . In cases of locked houses or where the key informant is not present the next household was approached.

For the Qualitative part of the research concerned key stakeholders in the selected blocks and municipalitieswere interviewed. BMOH of the blocks and Medical Officers in charge of Municipalities, the ASHAs and ANMs of the subcentre of the concerned rural clusters (villages) were interviewed using one interview guide.Data were compiled and analyzed using R.

\section{Results}

The results of the survey were as follows. MDA Coverages of both DEC and Albendazole in Takipur, Bilkinda, Madhyamgram and Birati were $97.9 \%, 95.1 \%, 98.1 \%$ and $27.5 \%$ respectively, with overall coverage being $81.9 \%$. The coverage in Birati was significantly poor as compared to other clusters was significant ( $\chi^{2}$ 306.26, df $1, \mathrm{p}<0.05)$.

Out of 447 individuals among whom the drugs w ere distributed, only 386(86.3\%) individuals consumed. So, the effective coverage was estimated to be $86.3 \mathrm{X} 81.9=70.7 \%$ percent which is below the cut-off level ( $\geq 85$ percent) for the programme requirement.Only $4.7 \%$ of the study subjects consumed drugs under supervision. The highest effective coverage was found in Madhyamgram (90.5\%) and poorest in Birati (11.7\%). (Table 1)

$23(17.9 \%)$ of the surveyed households did not receive any drug (implyingthat these households were not covered or reached). These percentages were highest (68.7\%) in Birati urban cluster and lowest (0\%) in both the rural clusters (Takipur and Bilkinda) withMadhyamgram urban cluster found to be a very close follower $(3.1 \%)$. Non Compliant households (105) (those who received both drugs but took none) were higher in higher Socio Economic Groups and more educated families (according to education and income of head of the family), but this trend was not found to be statistically significant. (Table 2)

With regards to non compliant subjects (447 in total), the difference in compli ance in rural and urban areas was not significant $(\chi 21.5936$, df $1, \mathrm{p}>0.05)$. Compli ance was almost equal in males and females too and difference was non-significant $(\chi 20.0252$, df $1, \mathrm{p}>0.05)$. Hindus $(16.5 \%)$ are found to be more non-compliant than Muslims and difference was significant $(\chi 25.6937, \mathrm{df} 1, \mathrm{p}<0.05)$.(Table 3)

Only $2.3 \%$ (9) of the study subjects who had consumed MDA drugs developed at leastone adverse effect and amongst which nausea and drowsiness were most common (33.3\% each). The predominant reason of noncompliance was found to be peopleconsidering the intake of drug as 'not necessary' (32.8\%) followed by 'fear of side effects' (31.1\%) of the drug.

The drugs were distributed mostly by ASHAs and in some cases by other workers.The DEC was distributed in the packets which were supplied and Albendazole as lose drugwrapped with paper.Only $4.7 \%$ of the study subjects consumed drugs under supervision.Supervision rate was highest at Takipur (9\%), with $0 \%$ at Bilkinda I and Birati. Among the 'Unsupervised consumers' $69.3 \%$ (255 out of 368 ) consumed drugs on the same day.Also only $4.7 \%$ of the study subjects consumed the drug immediately. The main reason fordelayed consumption was found to be the instruction of consuming the drugs after meals $(85.8 \%)$.

\section{Discussion}

Consumption of DEC and Albendazole tablets by $>85 \%$ population and sustaining for 5 yearsis the most crucial criteria of anti filaria programme to achieve the desired elimination and deminish the parasite load below the level of transmission $(<1 \%){ }^{(4)}$

In our study, coverages of DEC and Albendazole in Takipur, Bilkinda, Madhyamgram and Birati were $97.9 \%, 95.1 \%, 98.1 \%$ and $27.5 \%$ respectively, with overall coverage being $81.9 \%$, which is low for national target. One urban area has got significantcoverage of $98.1 \%$. The entire coverage data is pulled down by Birati Municipality with apoor coverage of $27.5 \%$. The rural areas are showing more consistent coverage. Similar study by Kumar $\mathrm{P}$ et al in Gujarat also showed that $\mathrm{b}$ oth coverage and compliance were marginally better in rural areas than in urban areas, and accordingly the actual coverage too was better in rural areas. ${ }^{(5)}$

The effective coverage of Takipur, Bilkinda I, Madhyamgram and Birati was estimated to be $91.7 \%, 77.9 \%$, $90.5 \%$ and $11.5 \%$ respectively. If we exclude Birati then the effective coverage for the rest of the three clusterscomes out to be $86.7 \%$ which is above the cut-off level ( $\geq 85$ percent) for the programme requirement. 
Post-MDA survey conducted in 2010 in North 24Paraganasby Karmakar et al. reported only $55.9 \%$ coverage and $69.4 \%$ compliance making effective coveragerate $38.8 \%$, much lower than that of the present study. ${ }^{(6)}$ In a study by R.N.Roy et al t he proportion of effective coverage was $41.18 \%$ and $20 \%$ in $6-14$ years and $2-5$ years age-group respectively. ${ }^{(7)}$

Hindus $(16.5 \%)$ are found to be more non-compliant than Muslims, and for the other factors, thestrata are comparable with respect to coverage.In the present study, $13.7 \%$ of population failedto consume the drug even after receiving it, which was more or less similar (around 14\%) to thatreported in another study ${ }^{(7)}$.

Study by D.Haldar et al also showed that $\mathrm{t}$ he most common cause of noncompliance was found to be "fear of side effects" (63.02\%) followed by other reasons like "not aware or counselled" (24.48\%), "belief that no drug is required for a healthy individuals" $(13.54 \%)$, and "not at home" $(7.81 \%)^{(8)}$, a finding that goes concurrently with this study.

Dr P. Ray Karmakar et al and Roy R.N et al study on MDA coverage also found that the main cause for delayed drug consumption was the tendency to consume them after meals, a finding which has been highlighted in this survey also.

Only $2.3 \%$ (9) of the study subjects who had consumed MDA drugs and developed at leastone adverse effect and amongst which nausea and drowsiness were most common (33.3\% each). Side-effects reported by other researchers ${ }^{(6,7)}$ were more or less similar as reported in thepresent study.

The present studywas not free of limitations.Apart from the possibility of recall bias, $\mathrm{t}$ he study should have obtained more qualitative inputs in form of FGDs of ASHAs, clients. A better representation by cluster sampling could have been done with more fundsand time.

\section{Reference}

[1]. India. Directorate General of Health Services. National Filaria Control Programme (NFCP), Ministry of Health \& Family Welfare available from http://nvbdcp.gov.in/fil5.html accessed on 13-08-2015.

[2]. West Bengal. State Bureau of Health Intelligence, Directorate of Health Services. Health On The March 2012-2013. Government of West Bengal. page 113.

[3]. Kumar P, Prajapati PB, Saxena D, Kavishwar AB Wynd S, Melrose D W,Durrheim D N, Carron J, Gyapong M. Understanding the community impact of lymphatic filariasis: a review of the sociocultural literature. Bulletin of the World Health Organization. available from http://www.who.int/bulletin/volumes/85/6/06-031047/en/ accessed on 14-08-2015.

[4]. Park K.Textbook of Preventive and Social Medicine. 23nd Edition 2015 Jabalpur India: M/s BanarasidasBhanot page 270.

[5]. Kurian J. An evaluation of coverage and compliance of mass drug administration 2006 for elimination oflymphaticfilariasis in endemic areas of Gujarat. Indian J Community Med2008;33:38-42.

[6]. Karmakar P.R, Mitra K, Chatterjee A,Jana P.K, Bhattacharya S,Lahiri S.K. A study on coverage, compliance and awareness about massdrugadministration for elimination of lymphatic filariasis in adistrict of West Bengal, India. J Vector Borne Dis 48, June 2011, pp. 101-104.

[7]. Roy R.N, Sarkar A.P, Misra R, Chakroborty A, Mondal T.K, Bag K study on Coverage and Awareness of and Compliance with Mass Drug Administration for Elimination of Lymphatic Filariasis in Burdwan District, West Bengal, India,J Health PopulNutr. 2013 Jun; 31(2): 171-177. available from http://www.ncbi.nlm.nih.gov/pmc/articles/PMC3702337/

[8]. Haldar D, Ghosh D, Mandal D, Sinha A, Sarkar G.N, Sarkar S study. Is the coverage of mass-drug-administration adequate for elimination of Bancroftianfilariasis? An experience from West Bengal, India avalable fromhttp://www.tropicalparasitology.org/article.asp?issn=2229-

$5070 ;$ year $=2015 ;$ volume $=5 ;$ issue $=1$; spage $=42$; epage $=49$; aulast $=$ Haldar accessed on 13-08-15.

\section{Tables}


Table 1: Distribution of eligible participants according to drug distribution $(\mathrm{N}=546)$

\begin{tabular}{|c|c|c|c|c|}
\hline Selected Cluster & $\begin{array}{l}\text { Both DEC } \\
\text { and } \\
\text { Albendazol } \\
\text { edistribute } \\
\quad \text { d }\end{array}$ & $\begin{array}{c}\text { Both } \\
\text { DEC and } \\
\text { Albendaz } \\
\text { ole } \\
\text { consume } \\
\text { d }\end{array}$ & $\begin{array}{c}\text { Consum } \\
\text { ed, } \\
\text { Supervis } \\
\text { ed }\end{array}$ & $\begin{array}{l}\text { Effective } \\
\text { Covergae }\end{array}$ \\
\hline Takipur $\left(\mathrm{n}_{1}=145\right)$ & $142(97.9)$ & $133(93.7)$ & 12(9) & 91.7 \\
\hline Bilkinda( $\left.\mathrm{n}_{2}=122\right)$ & $116(95.1)$ & $95(81.9)$ & 0 & 77.89 \\
\hline$\underset{9)}{\operatorname{Madhyamgram}\left(n_{3}=15\right.}$ & $156(98.1)$ & $144(92.3)$ & $6(4.2)$ & 90.5 \\
\hline Birati $\left(\mathrm{n}_{4}=120\right)$ & $33(27.5)$ & $14(42.4)$ & 0 & 11.7 \\
\hline Total $(N=546)$ & 447 (81.9) & $386(86.4)$ & $18(4.7)$ & 70.7 \\
\hline
\end{tabular}

Figures in parentheses denote percentages*calculated as a percentage of both drugs received

Table 2: Distribution of Households (who received drugs)according to non-compliance and sociodemographic characteristics of the head of the household $(n=105)$

\begin{tabular}{|c|c|c|}
\hline Category & Number & $\begin{array}{c}\text { Non-Compliant } \\
\text { No. (\%) }\end{array}$ \\
\hline \multicolumn{3}{|c|}{ Education of Head of Family } \\
\hline Illiterate & 36 & $4(11.1)$ \\
\hline Up to primary & 22 & $4(18.2)$ \\
\hline Primary & 31 & $5(16.1)$ \\
\hline Secondary/above (10 years or above) & 16 & $4(25.0)$ \\
\hline Modified B G Prasad Scale (2013) \\
\hline Class V & 35 & $6(17.1)$ \\
\hline Class IV & 49 & $9(18.4)$ \\
\hline Class III & 16 & $1(6.3)$ \\
\hline Class II & 3 & $1(0.0)$ \\
\hline Total & 2 & $17(16.2)$ \\
\hline
\end{tabular}

Table 3: Distribution ofparticipantswith respect tocompliance and socio demographic characteristics $(n=447)$

\begin{tabular}{|c|c|c|}
\hline Parameter & $\begin{array}{c}\text { Number } \\
\text { (who has received both tablets) }\end{array}$ & $\begin{array}{c}\text { Non Compliant } \\
\text { No(\%) }\end{array}$ \\
\hline Age (in years) & 32 & $4(12.5)$ \\
\hline $2-5$ & 58 & $11(18.9)$ \\
\hline $6-14$ & 357 & $46(12.9)$ \\
\hline$>=15$ & & $31(13.4)$ \\
\hline Sex & 232 & $30(13.9)$ \\
\hline Male & 215 & $52(16.5)$ \\
\hline Female & & $9(6.9)$ \\
\hline Religion & 316 & $31(12.4)$ \\
\hline Hindu & 131 & $22(14.3)$ \\
\hline Muslim & & $8(18.6)$ \\
\hline Caste & 250 & $30(11.6)$ \\
\hline General & 154 & $31(16.4)$ \\
\hline SC & 43 & $61(13.6)$ \\
\hline OBC & & \\
\hline Locality & 258 & \\
\hline Rural & 189 & \\
\hline Urban & 447 & \\
\hline Total & & \\
\hline & & \\
\hline
\end{tabular}

